Rimak International Journal of Humanities and Social Sciences

ISSN: 2717- 8293

Youssef ABBOU 1

SUPERVISED : Pr. Najat BELARBI \& Pr. Ismail ALAOUI

\title{
THE INFLUENCE OF EMOTION ON COGNITIVE PROCESSES IN LEARNING CONTEXT \\ http://dx.doi.org/10.47832/2717-8293.1-3.11
}

\begin{tabular}{l}
\hline Research Article \\
\hline Received: \\
18/11/2020 \\
Accepted: \\
19/12/2020 \\
Published: \\
01/01/2021 \\
\hline This article has been \\
scanned by iThenticat \\
No plagiarism detected \\
Copyright C Published \\
by Rimak Journal, \\
www.rimakjournal.com \\
Rimar Academy, Fatih, \\
Istanbul, 34093 Turkey \\
All rights reserved \\
\hline
\end{tabular}

\begin{abstract}
:
Indeed, probing the learning and acquisition processes, and perfecting its methods in terms of acquiring knowledge, and achieving academic success from within the research in the psychology of intelligence in general, has been the main focus in modern psychology. But aside from this early interest in the relationship of intelligence, in general terms, with cognitive competencies and school learning, has been officially recognized as a field of study during the nineties of the last century of the great impact and influence of emotional factors helped achieve compatibility and played a major role in academic success. Hence, the significance of this work is to highlight the importance of emotional factors and their role in motivating the students and enabling them to be aware of thier mental capabilities and cognitive competencies, emphasizing the need to focus on the positive aspects of thier cognitive processes, and all that is nourished and saturated with pedagogical practices and (didactic) teaching methods. As a result intimidation and frustration are replaced by encouragement, dialogue and flexibility reject repression. Toughness and isolation let the floor for interaction and participation. Positivity becomes one the main goals that we seek to achieve through this work in order to emphasize the importance of student's motivation, the necessity of educational motivational communication, the attractiveness of the cognitive material in school subjects, as well as giving importance to the student and make him the center of the teaching-learning process so that he becomes self-independent ,free and able to be more creative while thinking. While the general problematic of this research which takes cognitive psychology as its background, and positive psychology its theoretical model - can be summarized in determining the nature of the relationship between emotiona and learning, and how emotional variables and affects states effect the student's learning and acquisition process.
\end{abstract}

\footnotetext{
${ }^{1}$ Researcher, Sidi Mohamed Ben Abdellah University, Morroco, you-ssef01@hotmail.fr, https://orcid.org/0000-0002-6163-7115
} 
Key words: Positive Psychology, Learning, Cognitive Processes, Emotion, Motivation.

\section{Introduction:}

Learning is an essential topic at cognitive psychology, as this concept has become the process that unifies the cognitive, emotional, and motivational dimension in an integrated dynamic system. Most recent studies focused on one of these variables in its relationship to the concept of learning, where the interest was often either on the role of motivation in stimulating the students's higher cognitive processes. (Barry \& Schunk, 2003, p. 446). Or focus on the role of metacognitive in academic achievement. (Grover, 2011, p. 130). But in all cases the emotional dimension was neglected, until the emergence and evolution the Emotional sciences, which focused on highlighting the importance of the emotional variables and its role in stimulating the students and enabling them to be aware of their capabilities and potentials, by relying findings of neurosciences, regarding the brain structure and functions, which can provide a Nurological interpretation of the relationship between emotion, cognition, and motivation. (Uttl, Ohta, \& Siegenthaler, 2006, p. 107). Thus, emotions make students more active and engaging cognitively, which suggests that they will think deeply and critically about the tasks contents as well as their ability to complete these tasks successfully. In connection with that, this article acquires its importance and scientific value by highlighting the importance of emotional states, as variables that effect on student's cognitive functioning in learning context, which are variables that have been often neglected or underestimated, in the process of the learning and building the academic lessons. Based on the foregoing, we can pose these questions: What is the relationship between emotions and learning? How do emotional states affect the student's cognitive and metacognitive processes? How do emotional factors improve learning?

\section{1. from Cognitive to Metacognitive}

According to Bandura (1997) in behavior theory, learning through paired experience, labeled classical conditioning, is commonly viewed as a process wherein conditioned stimuli are directly and automatically connected to responses evoked by unconditioned stimuli. Conditioning is simply a descriptive term for learning resulting from paired stimulation, not an explanation of how the changes come about. (Bandura, 1977, p. 67). By the other hand, Sternberg (2009) reports that by the end of the 1950s some psychologists were intrigued by the tantalizing notion that machines could be programmed to demonstrate the intelligent processing of information. He shows that artificial intelligence (AI) is the attempt by humans to construct systems that show intelligence and, particularly, the intelligent processing of information. He states that the chess-playing programs, which now can beat most humans, are examples of artificial intelligence. (Sternberg, 2009, p. 11). In connection with that, deep learning is a special kind of learning with deep artificial neural networks, although today deep learning and artificial neural networks are considered to be the same field. Artificial neural networks are a subfield of machine learning which is in turn a subfield of both statistics and artificial intelligence (AI) Artificial neural networks are vastly more popular in artificial intelligence than in statistics. Deep learning today is not happy with just addressing a subfield of a subfield, but tries to make a run for the whole AI. (Skansi, 2018, p. 6). Many of the early cognitive 
psychologists became interested in cognitive psychology through applied problems. This issue made them later to focus on frontal lobes to find out the higher mental functions and the cognitive processes that permit us to perform more complex aspects of behavior, Cognitive control, or what is sometimes referred to as executive function, allows us to use our perceptions, knowledge, and goals to bias the selection of action and thoughts from a multitude of possibilities. In thier book "Cognitive Neuroscience, The Biology of the Mind" Gazzaniga, Ivry, and Mangun (2014) assumes that cognitive control processes allow us to override automatic thoughts and behavior, and step out of the realm of habitual responses. They give us cognitive flexibility, in addition they letting us think and act in novel and creative ways. By being able to suppress some thoughts and activate others, we can simulate plans and consider the consequences of those plans. (Gazzaniga, Ivry, \& Mangun, 2014, p. 508).

\section{A. Learning Abbility}

Sternberg and Pretz (2005) argues in their book "Cognition and Intelligence: Identifying the Mechanisms of the Mind" that one intuitive prediction that has existed in the intelligence literature from its inception is the hypothesis that intelligence is the ability to learn. (Sternberg \& Pretz, 2005, p. 312). In this context, Sternberg and Zhang (2001) reports: "traditionally, many psychologists and educators have believe that people's successes and failures are attributable mainly to individual differences inabilities. For the past few decades, however, investigators have been studying the roles of thinking, learning, and cognitive styles in performance with both academic and nonacademic settings." (Sternberg \& Zhang, 2001, p. 9). Among this, Bassham et al. (2011) argues that students must, be able to understand the material they are studying. According to them a course in critical thinking can't make inherently difficult material easy to grasp, but critical thinking does teach a variety of skills that, with practice, can signifi cantly improve your ability to understand the arguments and issues discussed in their college textbooks and classes. (Bassham, Irwin, Nardone, \& Wallace 2011 , pp. 7, 8). By the other hand academic success for all students, and particularly for students with learning and attention difficulties, is connected with their motivation, academic self-concept, and self-efficacy. (Goldstein \& Naglieri, 2014, p. 447).

\section{B. Metacognition and Learning}

The simplest definition of metacognition is " cognition about cognition " a metacognitive process is meta-level with respect to an object-level cognitive process. (Fleming \& Frith, 2014, p. 2). According to Flavell (1979) and Baker (2002) metacognition can be broadly defined as cognition about one's own cognitive processes. Dunlosky, Hacker, and Graesser (2009) argues that most definitions of metacognition have focused on two separate but related aspects: (1) knowledge/awareness of cognitive processes, and (2) control of cognitive processes. (Dunlosky, Hacker, \& Graesser, 2009, p. 27). Beran, Brandl, Perner, and Proust (2012) Flavell (1979) has distinguished between three major components of metacognition: metacognitive knowledge, metacognitive experiences, and metacognitive skills, that is strategies controlling cognition. Declarative metacognitive knowledge has been studied in children as young as 4 or 5 years in interview studies of metamemory, as well as in tasks requiring a judgement of the difficulty of a memory problem or a strategy choice. (Beran, Brandl, Perner, \& Proust, 2012, p. 119). On this basis Kourken (2016) concluded that metacognition can likewise play an 
important role in enabling agents to attain high levels of power and speed in belief formation. (Kourken, 2016, p. 150).

\section{Metacognition in the Classroom}

The notion that metacognition should be investigated in classroom practice is a theme that is particularly attractive as a research path. We pay lip service, on the whole, to bringing cognitive psychology out of the laboratory, but we have not been as diligent about this as we could be (with several notable exceptions). Metacognition research in classroom settings affords us the opportunity to know, in a unique way, whether our teaching methods are optimal because metacognition allows us to look at the constructed understanding of our classroom teaching. Metacognition research also informs educators about other important issues that educators frequently fail to grasp, for example, that subjective mastery can be very different from objective mastery of learned material. Koriat, Sheffer, and Ma'ayan (2002) and many others have made the point that differences between subjective knowing and objective performance can give rise to illusions of knowing, with serious consequences .(Dunlosky \& Bjork, 2008, p. 411). for students' grades. Teaching for objective mastery can be greatly enhanced by a concomitant understanding of what the learner understands about the learning process. In this chapter, I draw on research in metamemory over two decades that shows the importance of understanding what the learner believes or thinks he or she knows about his or her own learning, about what works in the process of memorizing. When this is set alongside objective memory outcomes, the results can be very surprising for educators. I am very selective in the experiments I describe, choosing some of those that exemplify earlier metacognitive studies that also have direct relevance to the classroom. The topics covered are the relativity of metacognitive judgments and their dependence on context; illusions of learning; metacognitive judgments about memory for text; and a new metacognitive judgment - the judgment of source. I conclude with some general implications for classroom practice. (Dunlosky \& Bjork, 2008, p. 412).

\section{Domains of Application}

Perfect and Schwartz (2004) shows that Dunlosky and colleagues investigated how practicing can help improve metacognitive monitoring, They argues that encouraging people to take practice tests can improve their ability to predict how they will do on the actual tests. In this way, practice testing may help people to study more effectively. By the other hand, Perfect and Schwartz, Mazzoni and Kirsch examine the role of metacognitive beliefs in the retrieval of autobiographical memories and discuss the implications in legal and clinical settings. In their model, people use metacognitive criteria to assess the veracity of retrieved memories. Furthermore, metacognitive beliefs are also used to assess if the inability to retrieve a memory implies that person did not witness or participate in an event. (Perfect \& Schwartz, 2004 , pp. 7,8$)$.

\section{Motivation}

Why do we do the things we do? Psychologists, philosophers, parents, educators and students, and employers and employees (among others) have long tried to understand the answer to this question. Historically, the field of psychology focused on two main types of explanations: basic biological needs or drives connected to survival and procreation (e.g., hunger, thirst, sex), 
and extrinsic rewards or punishments. According to these perspectives, motivation energizes and guides behavior toward a particular outcome. Researchers also began to recognize, however, that these two types of explanation were not sufficient. Rather, humans (and other animals) sometimes engage in behaviors that seem to be ends in themselves rather than a means to some outcome. Moreover, these behaviors appear to be associ- ated with positive feelings of interest, enjoyment, and satisfaction. Thus, researchers began to develop theories about "intrinsic" rewards and intrin- sic motivation, in which the rewards are inherent to the activity. (Sansone \& Harackiewicz, 2000, p. 18).

Bandura (1997) defined motivation as an all-encompassing construct comprised of a system of selfregulatory mechanisms. Motivation fuels the process in which an individual selects, activates, and directs behaviour towards a set goal. It is either constrained or reinforced through the expectations of the predicted outcomes of one's actions, as well as one's selfefficacy to perform such actions (Pintrich \& Schunk, 2002). The beliefs an individual houses about their capacity to succeed and to direct their actions not only impacts behaviour, but also the cognitive and affective processes underlying such behaviour (Schunk \& Zimmerman, 2008). When trying to understand the source of motivation it is therefore important to identify the determinant of behaviour, as well as any interacting factors (Bandura, 1991b, as cited in Bandura, 1997). In line with the Social Cognitive view of motivation, for any given task, an individual can be motivated in a multitude of ways, each of which interacts in a reciprocal fashion and bears influence on overall performance. (Mcgaugh, 1990, p. 29).

Fraser, Tobin, and Campbell (2012) concluded in thier Handbook of Science Education that Emotions are a central part of action; that is, when we act our emotions are put on display in how we move and use our bodies, including gestures, facial expressions, head movements, and speech. For example, when we are excited, those who are in sync with us experience our excitement as we interact with them. High-energy teachers, for example, communicate their emotions to a class in the ways they coordinate their bodily actions and characteristics of their speech. Similarly, if a person is angry, others having a history of interacting with that person can "read" the anger, because it is visible in the person's actions. Humans who have intense and prolonged experiences with others can quickly pick up their emotions based on just a small number of encounters - "Oh, she is in a bad mood, I should avoid her for a while!" Or, "he is angry, I should let him sort this out before I raise these issues with him." These are just two examples of the kinds of thoughts I have when I approach people that I know and quickly size up their emotions prior to commencing my interactions with them. In our research we have begun to zero in on ways to measure the emotional content of actions. (Fraser, Tobin, \& Campbell, 2012, pp. 14, 15).

\section{A. Directional Influences of Motivation on Cognitive Processes.}

Broadly defined, motivation is indicated by the intensity (or energy), direction, and persistence of a goal-directed behavior or action. Dweck's work on goal orientation (Dweck, 1999; Dweck, Mengals, \& Good, chap. 2) clearly emphasizes the direction aspect of motivation. In other words, motivation does not just kickstart a mental act, with the rest of the action carried out by cognitive processes. Goal orientation (whether the attentional focus is on the self or on the task to be learned, and what is the implicit or explicit purpose of engaging in the task) frames the mindset, and can 
significantly influence the allocation of attentional resources, effort expenditure, and emotional reactions to difficulties, and persistence in the face of setbacks. (Fraser et al., 2012, p. 11).

B. Motivational effects on attention and cognitive processing

Sternberg (2004) wonderd about the guides goal-related attentional and cognitive processes? According to him The cognitive mechanism that ensures goals are met can be seen as an executive control network responsible for directing attention toward goal-relevant information and away from goal-irrelevant information (e.g., Botvinick, Braver, Barch, Carter, \& Cohen, 2001; Posner \& DiGirolamo, 1998; Shallice \& Burgess, 1996). He assured that Selective attention toward goal-relevant information is typically evidenced as an increase in the speed, accuracy, or depth of information processing of that information. Given that entityandincre mental theorists hold contrasting goals, we would expect that the executive control network would direct their attention to different information and this difference might have consequences for how quickly, accurately or deeply different types of information are processed. For students with an entity theory of intelligence, this executive control network may bias attention and conceptual processing toward information that speaks to the adequacy or inadequacy of their intellectual ability (performance goal-relevant information) and not toward information that provides new knowledge that could help them improve. (Sternberg, 2004, pp. 45, 46).

\section{Emotion : From Cognitive to Emotional Sciences}

\section{A. What is an Emotion?}

One issue of research on emotions is that there are many definitions and theories of emotion. Early theories considered the physiological reactions as the basis of an emotion. According to this view, people feel sad because they cry. Appraisal theories, in contrast, assume that the evaluation and interpretation of situations play a central role in the experience of emotions. (Sassenberg \& Vliek, 2019, p. 207). Gazzaniga, Ivry, and Mangun (2014) wondres, how would we define emotion? In thier point of view, may be our definition starts with "An emotion is a feeling you get when..." And we already have a problem, because many researchers claim that a feeling is the subjective experience of the emotion, but not the emotion itself. Gazzaniga and colleagues suggested the definition of Kevin Ochsner and James Gross (2005), two researchers, According to them the emotions are valenced responses to external stimuli and/or internal mental representations that involve changes across multiple respons systems (e.g., experiential, behavioral, peripheral, physiological), are distinct from moods, in that they often have identifi able objects or triggers, can be either unlearned responses to stimuli with intrinsic affective properties (e.g., pulling our hand away when we burn it) or learned responses to stimuli with acquired emotional value (e.g., fear when you see a dog that previously bit you), can involve multiple types of appraisal processes that assess the signifi cance of stimuli to current goals, that depend upon different neural systems. Most psychologists agree that emotion consists of three components : 1 . a physiological reaction to a stimulus, 2. a behavioral response, and 3. a feeling. (Gazzaniga et al., 2014, p. 427).

\section{B. Emotional Brain Functioning}

The emotional brain is organized into a hierarchy of function proceeding from the reticular formation, including mesencephalic midbrain nuclei to the 
hypothalamus and thalamus to the limbic and neocortical regions. (Marcus \& Jacobson, 2003, p. 512). Gazzaniga and colleagues (2014) assured that many parts of the nervous system are involved in our emotions, When emotions are triggered by an external event or stimulus (as they oft en are), our sensory systems play a major role. Sometimes emotions are triggered by an episodic memory, in which case our memory systems are involved. The physiologic components of emotion (that shiver up the spine, or the racing heart and dry mouth people experience with fear) involve the autonomic nervous system (ANS), a division of the peripheral nervous system. And its motor and sensory neurons extend to the heart, lungs, gut, bladder, and sexual organs. The two systems work in combination to achieve homeostasis. (Gazzaniga et al., 2014, p. 328). Emotional Functions Models of the neuropsychological basis of emotions indicate that the frontal lobes play a central role in the processing of emotional responses. (Clikeman \& Ellison, 2007, p. 54). Yet where do emotions reside?

\section{The Limbic System as the Emotional Brain}

The limbic system structures that are part of the temporal lobe include the parahippocampal gyrus, the entorhinal cortex, the hippocampal formation, the uncus, and the amygdala. Clark, Boutros, and Mendez (2010) shows that the cortex of the temporal pole is sometimes considered limbic. All sensory information from the external world passes through unimodal and multimodal association areas before finally converging on the hippocampus and amygdala. These structures can be considered to be supramodal centers. (Clark, Boutros \& Mendez, 2010, p. 176).

\section{The Hippocampus}

The hippocampus is phylogenetically the older part of the cerebral cortex termed allocortex and consists of three layers: polymorphic, pyramidal, and molecular. The dentate gyrus fits inside the hippocampus and, like the hippocampus, has three layers: molecular, granular, and polymorphic. The most primitive cortex is the paleocortex of the olfactory bulb. (Marcus \& Jacobson, 2003, p. 496). Hippocampal structures have been implicated in both cognitive and emotional processes, The hippocampal formation deals with two forms of information. One form arrives from other areas of the cortex, is cognitive in nature, and enters by way of the entorhinal cortex. The other form arrives from the septum, amygdala, hypothalamus, and brainstem, and is related to the behavioral/emotional state. (Clark et al., 2010 , p. 178). Long-term storage of episodic memories is hypothesized to result from the information transfer from the hippocampus to the neocortex over time. This information restructuring should be accompanied by the change in the neural circuits and is thought to be mediated by reactivation of the same patterns of neural activity that are present during a previous experience. (Tsukiura \& Umeda, 2017, p. 20). According to Golman (2009) research by LeDoux and other neuroscientists now seems to suggest that the hippocampus, which has long been considered the key structure of the limbic system, is more involved in registering and making sense of perceptual patterns than with emotional reactions. According to Golman The hippocampus's main input is in providing a keen memory of context, vital for emotional meaning; it is the hippocampus that recognizes the differing significance of, say, a bear in the zoo versus one in your backyard. (Goleman, 2009, pp. 50, 51).

\section{The Amygdala}


The short answer to the question of the functional significance of the amygdala is that it appears to play an important role in the attachment and/or recognition of emotional valences associated with our sensory experiences. (Mendoza \& Foundas, 2008, p. 231). By the other hand, Debiec, Heller, Brożek, and LeDoux (2014) reports in thiere book "The Emotional Brain Revisited " that amygdala plays a major role in the resolution of predictive uncertainty associated with fearful faces, surprised facial expressions provide a particularly important comparison expression. Indeed, there is evidence that surprise may be the second-most compromised expression in patients with selective amygdala damage, following fear. (Dębiec, Heller, Brożek, \& LeDoux, 2014, p. 125). They demonstrate that the lateral amygdala is important in the acquisition and retention of memories of emotional experiences. Evidence indicates that memory is not stored in the amygdala but that activity within the amygdala consolidates memory elsewhere in the brain. Norepinephrine release within the amygdala appears to be critical for memory formation. Norepinephrine from the adrenal medulla activates vagus nerve receptors, which send signals to the solitary nucleus in the brainstem. (Clark et al., 2010, p. 181). According to Golman while the hippocampus remembers the dry facts, the amygdala retains the emotional flavor that goes with those facts. He assured that if we try to pass a car on a two-lane highway and narrowly miss having a head-on collision, the hippocampus retains the specifics of the incident, like what stretch of road we were on, who was with us, what the other car looked like. But it is the amygdala that everafter will send a surge of anxiety through us whenever we try to pass a car in similar circumstances. As LeDoux put to Golman: "The hippocampus is crucial in recognizing a face as that of your cousin. But it is the amygdala that adds you don't really like her." (Goleman, 2009, p. 51).

\section{Emotion and Cognition}

Gazzaniga and colleagues (2014) argues that the notion that emotion is separate from cognition and has its own network of brain structures underlying emotional behavior is not new. To prove thier point of view, they provided a set of evidence for this, according to them, James Papez (pronounced "payps") proposed a circuit theory of the brain and emotion in 1937, suggesting that emotional responses involve a network of brain regions made up of the hypothalamus, anterior thalamus, cingulate gyrus, and hippocampus. (Gazzaniga et al., 2014, p. 482). By the other hand, Mandler cogently pointed out that we live in a world of artifacts, not only in terms of tools we invented, but in terms of folk beliefs and values shared in a community of culture or subculture. These folk beliefs and values can be just as powerful a regulator of emotion as biological needs. He discussed why math anxiety is a cultural phenomenon, and how playing math idiot can be a strategy of mental disengagement. Similarly, cross-cultural differences in implicit theories of intelligence and of learning reflect what is perceived as essential for effective functioning and what is important in the subjective culture of a community (Sternberg \& Yun Dai, 2004, p. 26). May be this is what made Bandura to suggested that there are social mechanisms that can alter the moral system by disengaging one's moral standards from action. That is, in Bandura's model, motivational processes are not fixed but must be activated to promote actions based on internalized moral standards. (Heinrichs, Oser, \& Lovat, 2013, p. 59).

\section{E. Emotion and Learning}


Historically, the field of psychology focused on two main types of explanations: basic biological needs or drives connected to survival and procreation (hunger, thirst, sex), and extrinsic rewards or punishments. Recently, Kluwe, Luer, and Rosler (2003) argues that learning in higher species is unlikely to reside in a single brain area and unlikely to be based on a single unitary mechanism. Even simple forms ofexperience-related changes in the brain are associated with parallel changes in multiple structures. (Kluwe, Luer, \& Rosler, 2003, p. 15). Related to this, Gazzaniga et al. (2014) reports that we should addresse how emotion affects the various cognitive processes that have been discussed, For instance, if we are angry a bout something, we may find it hard to concentrate on reading a homework assignment. According to them if we are really enjoying what we are doing, we may not notice we are tired or hungry. When we are sad, we may find it difficult to make decisions or carry out any physical activities. How emotions modulate the information processing involved in cognitive functions such as learning, attention, and decision making? (Gazzaniga et al., 2014, p. 438). We can find a simple answer to this issue with Mcgaugh (1990) according to him The beliefs an individual houses about their capacity to succeed and to direct their actions not only impacts behaviour, but also the cognitive and affective processes underlying such behaviour. (Mcgaugh, 1990, p. 29).

\section{The influence of Emotion on Learning}

According to Watanabe, Hofman, and Shimizu (2017) the brain systems and processing involved in emotion in vertebrates have evolved considerably. (Watanabe, Hofman, \& Shimizu, 2017, p. 252). Neday, early in the 20th century, Swiss neurologist and psychologist Édouard Claparède greeted his patient and introduced himself, She introduced herself and shook his hand. Not such a great story, until we know that he had done the same thing every day for the previous five years and his patient never remembered him. She had Korsakoff's syndrome, characterized by an absence of any short-term memory. One day Claparède concealed a pin in his palm that pricked his patient when they shook hands. The next day, once again, she didn't remember him; but when he extended his hand to greet her, she hesitated for the first time. Claparède was the first to provide evidence that two types of learning, implicit and explicit, apparently are associated with two different pathways. (Gazzaniga et al., 2014, p. 439). Thus the emotional mind according to Golman is far quicker than the rational mind, springing into action without pausing even a moment to consider what it is doing. Its quickness precludes the deliberate, analytic reflection that is the hallmark of the thinking mind. (Goleman, 2009, pp. 554, 555).

\section{A. Implicit Emotional Learning}

We can noted with Gazzaniga and colleagues (2014) that the implicit learning is a type of Pavlovian learning in which a neutral stimulus (the hand shake) acquires aversive properties when paired with an aversive event (the pin prick). According to them This process is a classic example of fear conditioning. It is a primary paradigm used to investigate the amygdala's role in emotional learning. Fear conditioning is a form of classical conditioning in which the unconditioned stimulus is aversive. (Gazzaniga et al., 2014, p. 439). On this basis the implicit memory as Baars et al. (2007) found is not accompanied by conscious awareness that one has a memory; the memory's existence is inferred only from the effects it has on behavior. Implicit memories may be retrieved without an intention to remember. 
Priming effects are used extensively to test for implicit memory. Priming refers to the effect of a stimulus in creating readiness for a similar one. For example, showing a picture of a face will increase the processing efficiency of a following face, as measured by faster reaction time and greater accuracy. Priming can be either perceptual or conceptual. (Baars \& Gage, 2007, p. 260).

\section{B. Explicit Emotional Learning}

Gazzaniga et al. (2014) assured that The double dissociation clearly indicates that the amygdala is necessary for implicit emotional learning, but not for explicit emotional learning. This doesn't mean that the amygdala is uninvolved with e xplicit learning and memory, how do we know? To answer this question they gave an example of explicit emotional learning:

$\mathrm{Liz}$ is walking down the street in her neighborhood and sees a neighbor's dog, Fang, on the sidewalk. Even though she is a dog owner herself and likes dogs in general, Fang scares her. When she encounters him, she becomes nervous and fearful, so she decides to walk on the o ther side of the street. Why might Liz, who likes dogs, be afraid of this particular dog? Gazzaniga wondred, According to him there are a few possible reasons: For example, perhaps Fang bit her once. In this case, her fear response to Fang was acquired through fear conditioning. Fang (the CS) was paired with the dog bite, resulting in pain and fear (the UR) and an acquired fear response to Fang in particular. Liz may fear Fang for another reason; however, she has heard from her neighbor that this is a mean dog that might bite her. In this case she has no aversive e xperience linked to this particular dog. Instead, she learned about the aversive properties of the dog explicitly. (Gazzaniga et al., 2014, p. 443).

These were examples of both explicit emotional learning and implicit emotional learning. Working Memory can be viewed as input to different types of long-term memory, divided into Explicit and Implicit ones. Explicit learning and retrieval involves conscious knowledge, both for facts and autobiographical experiences. Memory for facts is called semantic memory, while autobiographical memory is also called episodic because it reflects life episodes. Working Memory can manipulate explicit memories, like words, numbers, semantic facts and autobiographical episodes. Implicit learning and retrieval involves primed tasks, highly practiced habits and motor skills. (Baars \& Gage, 2007, p. 262).

\section{The influence of Emotion on Perception and Attention}

According to Gazzaniga et al. (2014) there is no doubt that we have had the experience of being in the midst of a conversation and hearing our name mentioned behind us. They says in this regard:

We exhibit an increased awareness for and pay attention to emotionally salient stimuli. Attention researchers often use the attentional blink paradigm, in which stimuli are presented so quickly in succession that an individual stimulus is difficult to identify. When participants are told that they can ignore most of the stimuli-say, all the words printed in green and attend only to the few targets printed in blue-then participants are able to identify the targets. This ability, however, is limited by the amount of time between the target (blue) stimuli. (Gazzaniga et al., 2014, p. 446). 
Gazzaniga et al. (2014) argues that most recent studies have shown that when the left amygdala is damaged, then patients don't recognize the second target even if it is an arousing word. So they concluds that it appears that when attentional resources are limited, it is the arousing emotional stimuli that reach awareness, thus the amygdala again plays a critical role in enhancing our attention when emotional stimuli are present. (Gazzaniga et al., 2014, p. 446). According to them emotional learning involves an enduring change in sensory cortical tuning, and the other is that it produces a more transient change.

\section{Conclusion}

We can confirme - Based on the above - with Golman, on the role of emotions in even the most "rational" decision-making. In work with farreaching implications for understanding mental life, to highlight the importance of emotion, Golman puts Dr. Damasio's study, who has made careful studies of just what is impaired in patients with damage to the prefrontal-amygdala circuit. Their decision-making is terribly flawed-and yet they show no deterioration at all in IQ or any cognitive ability. Despite their intact intelligence, they make disastrous choices in business and their personal lives, and can even obsess endlessly over a decision so simple as when to make an appointment. (Goleman, 2009, p. 65). Emotions play an important role in store and retrive memories, over the past decade. (Wessel $\&$ Wright, 2004, p. 8). Thus emotional events According to Dolcos and colleagues are usually remembered better than neutral events. (Uttl, Ohta \& Siegenthaler, 2006, p. 107). The brain systems and processing involved in emotion in vertebrates have evolved considerably. (Watanabe, Hofman, \& Shimizu, 2017, p. 252). Therefore Good learning is based on enabling students to be aware of their abilities and capabilities, by employing the teacher for various motivational strategies that target the student's emotional dimension, relying on didactic styles, and effective pedagogical methods, in order to motivate them, and build a desire to learn in them. Cognitive awareness makes students more active and cognitively involved, which suggests that they will think deeply and critically about the task's content, as well as thier ability to complete this task successfully. On this basis lies the importance of taking into account the stuents's mental functioning and emotional dimension to bring about a change at thier behavior and knowledge structure, in order to ensure its compatibility with the educational context.

\section{References}

Aggarwal, C. C. (2018). Neural Networks and Deep Learning, Springer, Library of Congress.

Aukrust, G. V. (2011). Learning and Cognition in Education, Elsevier, Academic Press.

Baars, J. B., \& Gage, M. N. (2007). Cognition, Brain, and Consciousness, Introduction to Cognitive Neuroscience, First Edition, Elsevier, Academic Press.

Bandura, A. (1977). Social Learning Theory, Prentice-Hall.

Bassham, G., Irwin, W., Nardone, H., \& Wallace, J. M. (2011). Critical Thinking: A Student's Introduction, McGraw-Hill. 
Beran, J. M., Brandl, L. J., Perner, J., \& Proust, J. (2012). Foundations of Metacognition, First Edition, Oxford University Press.

Cheng, J. T., Tracy, L. J., \& Anderson, C. (2014). The Psychology of Social Status, Springer, Library of Congress.

Clark, L. D., Boutros, N. N., \& Mendez, F. M. (2010). The Brain and Behavior, An Introduction to Behavioral Neuroanatomy, Third Edition, Cambridge University Press.

Clikeman, M. S., \& Ellison, P. A. T. (2007). Child Neuropsychology: Assessment and Interventions for Neurodevelopmental Disorders, Second Edition, Springer.

Dębiec, J., Heller, M., Brożek, B., \& LeDoux, J. (2014). The Emotional Brain Revisited, Copernicus Center Press.

Dunlosky, J., \& Bjork, A. R. (2008). Handbook of Metamemory and Memory, Psychology Press.

Fleming, M. S., \& Frith D. C. (2014). The Cognitive Neuroscience of Metacognition, Springer, Dordrecht Heidelberg.

Fraser, J. B., Tobin, G. K., \& McRobbie, J. C. (2012). Second International Handbook of Science Education, Springer, Dordrecht Heidelberg.

Gazzaniga, S. M., Ivry, B. R., \& Mangun, R. G. (2014). Cognitive Neuroscience, The Biology of the Mind, Fourth Edition, Library of Congress.

Goldstein, S., \& Naglieri, A. J. (2014). Handbook of Executive Functioning, Springer, Library of Congress.

Goleman, D. (2009). Emotional Intelligence: Why it can matter More than IQ, Bloomsbury Publishing.

Hacker, J. D., Dunlosky, J., \& Graesser, C. A. (2009). Handbook of Metacognition in Education, First published, Routledge.

Heckhausen, J., \& Heckhausen, H. (2018). Motivation and Action, Third Edition, Springer, Library of Congress.

Heinrichs, K., Oser, F., \& Lovat, T. (2013). Handbook of Moral Motivation: Theories, Models, Applications, Sense Publishers.

Kluwe, R. H., Luer, G., \& Rosler, F. (2003). Principles of Learning and Memory, Springer, Library of Congress.

Kourken, M. (2016). Mental Time Travel: Episodic Memory and our Knowledge of the Personal Past, The MIT Press, Cambridge, Massachusetts.

Marcus, E. M., \& Jacobson, S. (2003). Integrated Neuroscience: A Clinical Problem Solving Approach, first edition, Springer, Library of Congress.

Mcgaugh, L. J. (1990). Brain Organization and Memory: Cells, Systems, and Circuits, Oxford University Press.

Mendoza, J. E., \& Foundas, A. L. (2008). Clinical Neuroanatomy: A Neurobehavioral Approach, Springer, Library of Congress.

Perfect, J. T., \& Schwartz, B. L. (2004). Applied Metacognition, Cambridge University Press.

Pessoa, L. (2013). The Cognitive-Emotional Brain: From Interactions to Integration, The MIT Press, Cambridge, Massachusetts.

Sansone, C., \& Harackiewicz, J. (2000). Intrinsic and Extrinsic Motivaion, The search for optimal Motivation and Performance, Academic Press. 
Sassenberg, K., \& Vliek. M. L. W. (2019). Social Psychology in Action: Evidence Based Interventions from Theory to Practice, Springer.

Skansi, S. (2018). Introduction to Deep Learning: From Logical Calculus to Artificial Intelligence, Springer, Library of Congress.

Sternberg, J. R., \& Zhang, L. F. (2001). Perspectives on Thinking, Learning and Cognitive Styles, First published by Lawrence Erlbaum Associates, Inc, Publishers, Routledge.

Sternberg, J. R., \& Dai, Y. D. (2004). Motivation, Emotion, and Cognition: Integrative perspectives on Intellectual Functioning and Development Lawrence Erlbaum Associates.

Sternberg, J. R., \& Pretz, J. E. (2005). Cognition and Intelligence: Identifying the Mechanisms of the Mind, Cambridge University Press.

Sternberg, J. R. (2009). Cognitive Psychology, Fifth Edition, Wadsworth.

Tsukiura, T., \& Umeda, S. (2017). Memory in a Social Context, Brain, Mind, and Society, Springer.

Uttl, B., Ohta, N., \& Siegenthaler, L. (2006). Memory and Emotion, interdisciplinary perspectives, First published, Blackwell Publishing, Oxford.

Watanabe, S., Hofman, A. M., \& Shimizu, T. (2017). Evolution of the Brain, Cognition and Emotion in Vertebrates, Springer.

Wessel, I., \& Wright, D. B. (2004). Emotional Memory Failures, Tayor \& Francis, Psychology Press

Zimmerman, J. B., \& Schunk, H. D. (2003). Educational Psychology: A Century of Contributions, Lawrence Erlbaum Associates Publishers. 